\title{
EFFECT OF WETTING AGENT AND CARBIDE VOLUME FRACTION ON THE WEAR RESPONSE OF ALUMINUM MATRIX COMPOSITES REINFORCED BY WC NANOPARTICLES AND ALUMINIDE PARTICLES
}

\begin{abstract}
Aluminum matrix composites were prepared by adding submicron sized WC particles into a melt of Al 1050 under mechanical stirring, with the scope to determine: (a) the most appropriate salt flux amongst $\mathrm{KBF}_{4}, \mathrm{~K}_{2} \mathrm{TiF}_{6}, \mathrm{~K}_{3} \mathrm{AlF}_{6}$ and $\mathrm{Na}_{3} \mathrm{AlF}_{6}$ for optimum particle wetting and distribution and (b) the maximum carbide volume fraction (CVF) for optimum response to sliding wear. The nature of the wetting agent notably affected particle incorporation, with $\mathrm{K}_{2} \mathrm{TiF}_{6}$ providing the greatest particle insertion. A uniform aluminide (in-situ) and WC (ex-situ) particle distribution was attained. Two different sliding wear mechanisms were identified for low CVFs $(\leq 1.5 \%)$, and high CVFs $(2.0 \%)$, depending on the extent of particle agglomeration.

Keywords: Al-WC, nanocomposites, aluminides, wetting agent, ball-on-disk
\end{abstract}

\section{Introduction}

It is well established that reinforcement with nano- and submicron sized particles can improve the mechanical properties of particulate reinforced aluminum matrix composites (PRAMCs) due to the synergistic action of several strengthening mechanisms, such as the load transfer effect, Hall-Petch strengthening, Orowan strengthening, thermal expansion coefficient mismatch and elastic modulus mismatch between the reinforcements and the metal matrix [1].

Various processing techniques have been used to prepare nano-PRAMCs, e.g. mechanochemical processing/sintering, reactive hot pressing, deformation processing, vapor phase processing, plasma spraying etc. However, these processes are costly and laborious especially when manufacturing large structural components and complex shapes [2]. An effective remedy for the complicated fabrication route, can be the application of conventional casting methods, due to assets such as, low cost, ease-to-handle advantages, mass production abilities, strong matrix-particle bonding, relatively easy control of matrix structure and near net shape [3]. Towards a casting based production, Aluminum Matrix Composites (AMCs) reinforced with nanoparticles of $\mathrm{SiC}$ [4], $\mathrm{B}_{4} \mathrm{C}$ [5], $\mathrm{Al}_{2} \mathrm{O}_{3}$ [3,6], $\mathrm{MgO}$ [7], $\mathrm{AlN}$ [8], $\mathrm{TiB}_{2}$ and $\mathrm{TiO}_{2}$ [9], fly ash [10], etc. have been investigated. However, conventional casting may lead to severe segregation owing to the tendency of the nanoparticles to agglomerate (due to their high surface energy).
An improvement of the particle-molten alloy wetting behavior could limit the drawback of segregation. The wettability of ceramic nano-particles can be improved through two approaches:

(a) Development of unconventional casting techniques, such as liquid casting (ultrasound assisted casting, selective laser melting, disintegrated melt deposition, high pressure die-casting etc.) and semi-solid casting (combined rheocasting and squeeze casting, SSC (Semi-Solid Casting) etc.) [1]. Toward this direction, ultrasound assisted casting is a promising route but it is an expensive technique [2] and requires a large source of ultrasound waves [11].

(b) Adoption of a combination of simple wettability improving measures, whilst persisting in keeping the costs of conventional casting at reasonable levels, namely: (b1) Introduction of ceramic phases of strong metallic character, such as WC. Research, however, on cast AMCs reinforced with WC particles is fairly limited. WC is of high technological interest, as it is characterized by exceptionally high hardness, modulus of elasticity, excellent wear and high temperature corrosion behavior. Moreover, just a small amount of heavy refractory powder as a reinforcement is enough to lead to notable mechanical property improvements [12]. Fabrication of AMCs reinforced by WC micro-particles by powder metallurgy and casting methods is currently receiving a growing research attention owing to a significant improvement of mechanical properties (at the expense, however, of ductility [13]) and increase in the wear resist-

\footnotetext{
* DEPARTMENT OF MATERIALS SCIENCE \& ENGINEERING, UNIVERSITY OF IOANNINA, IOANNINA 45110, GREECE

** UNIVERSITY OF MISKOLC, MISKOLC-EGYETEMVÁROS, HUNGARY

\# Corresponding author: alekatou@cc.uoi.gr
} 
ance $[14,15]$. (b2) Application of mechanical stirring that can support the favorable wetting characteristics of less than $90^{\circ}$ contact angle and provide the necessary shear forces for total particle insertion [16]. (b3) Use of wetting agents (commonly fluoride salts) that promote the intimate contact between ceramic particles and molten alloy by dissolving surface oxides [17-21].

A crucial issue when dealing with AMCs is their wear response, as it may control their long-term performance and serviceability. The sliding wear response of PRAMCs is affected by many factors associated with the application conditions/testing parameters and nature of the AMCs (i.e. features of reinforcing phases and matrix), which have analytically been reported in previous works [22-24]. However, a uniform wear mechanism cannot be established, since a simultaneous contribution of several key factors can lead to severe complexity [25]. Literature on the wear performance of cast nano PRAMs is scarce: Nano $\mathrm{Al}_{2} \mathrm{O}_{3}$ reinforced $\mathrm{Al}$ showed lower wear loss than the monolithic alloy [6]. Rana et al [26] reported that, at a low load and short sliding distance, AA5083 reinforced with $\mathrm{SiC}$ nanoparticles displayed higher wear resistance than its microsized counterpart; this trend was reversed, at high load and longer sliding distance. Ekka et al [27] found that nano-SiC PRAMCs displayed better dry sliding wear resistance than nano- $\mathrm{Al}_{2} \mathrm{O}_{3}$ PRAMCs.

This work continues a preliminary study [22] within the framework of manufacturing competitive PRAMCs by following four main directions: a) adopting low cost, simple fabricating techniques, b) using ceramic nanoparticles as primary additions to exploit the advantages of the ultra-fine size, c) using low particle additions to reduce particle clustering and raw material costs and d) pursuing secondary in-situ reinforcing particle formation for further property improvement. The present effort has two objectives: a) to investigate the effect of a series of salt fluxes on the WC particle incorporation and the wear behavior of the resulting composites, b) to determine the highest WC particle addition into the alloy melt before deterioration of wear performance starts.

\section{Experimental}

PRAMCs were synthesized by the introduction of submicron WC particles (of 200-400 nm particle size and 0.5, 1.0, $1.5,2.0$ vol\% content) into $\mathrm{Al} 1050 . \mathrm{KBF}_{4}, \mathrm{~K}_{2} \mathrm{TiF}_{6}, \mathrm{~K}_{3} \mathrm{AlF}_{6}$ and $\mathrm{Na}_{3} \mathrm{AlF}_{6}$ were utilized as fluxing salts (quantities equimolar to WC addition). First, mixing of the reinforcement and salts was conducted. Then, this mixture was added into the alloy melt $\left(830^{\circ} \mathrm{C}\right)$. The salts were allowed to react with $\mathrm{Al}$; a slag was formed; the carbide particles infiltrated into the melt and the slag was removed by a ladle. Mechanical stirring (3220 rpm, 20 s) was employed for homogenization and breakage of any initial particle clusters. The load was cast into cylindrical, steel molds (1.5 cm inner diameter, $15 \mathrm{~cm}$ height).

Sliding wear experiments were performed on polished specimens $(\mathrm{Ra}<1 \mu \mathrm{m})$ at a CSM ball-on-disc tribometer under the parameters: load of $1 \mathrm{~N}$, sliding speed of $10 \mathrm{~cm} / \mathrm{s}$, sliding distance of $1000 \mathrm{~m}, 100 \mathrm{Cr} 6$ counter-body steel balls. Each run was interrupted every $200 \mathrm{~m}$, for measuring the mass loss of the sample. Metallographic examination was performed by SEM/ EDX (JEOL JSM 6510LV SEM/ Oxford Instruments X-Act EDX).

\section{Results and discussion}

\subsection{Effect of different wetting agents on the microstructure of the composites}

Among the different fluxing agents used in the present effort, $\mathrm{K}_{3} \mathrm{AlF}_{6}$ and $\mathrm{Na}_{3} \mathrm{AlF}_{6}$ remained unaffected at the melt surface not having any beneficial effect on particle insertion. $\mathrm{KBF}_{4}$ and $\mathrm{K}_{2} \mathrm{TiF}_{6}$ salts, on the other hand, led to a successful incorporation of WC particles. Both of these salts reacted with the aluminum melt. A liquid slag was formed on the melt surface with a great affinity for oxide phases. This affinity led to the dissolution of the oxide phase; thus, $\mathrm{Al}$ and $\mathrm{WC}$ were allowed to express their real wetting characteristics, which were expected to be intensive because of: a) the strong metallic character of WC, (b) the very fine particle size of WC and (c) the relatively high enthalpy of WC formation (-40.5 kJ/mole) [28]. Under these circumstances, a successful particle incorporation resulted, as shown in Fig. 1a-e.

In order to discuss the effect of $\mathrm{K}_{2} \mathrm{TiF}_{6}$ and $\mathrm{KBF}_{4}$ on the attained microstructures, one has to consider the reactions taking place during the whole manufacturing process, in accordance with the involved phase diagrams [29] and the work of El-Mahallawy [30]):

$$
\begin{gathered}
830^{\circ} \mathrm{C}: 19 \mathrm{Al}(\mathrm{l})+3 \mathrm{WC} \rightarrow 3 \mathrm{Al}_{5} \mathrm{~W}+\mathrm{Al}_{4} \mathrm{C}_{3} \\
16 \mathrm{Al}(\mathrm{l})+3 \mathrm{WC} \rightarrow 3 \mathrm{Al}_{4} \mathrm{~W}+\mathrm{Al}_{4} \mathrm{C}_{3} \\
3 \mathrm{~K}_{2} \mathrm{TiF}_{6}(\mathrm{~s})+13 \mathrm{Al}(\mathrm{l}) \rightarrow 3 \mathrm{Al}_{3} \mathrm{Ti}(\mathrm{s})+ \\
+3 \mathrm{KAlF}_{4}(\mathrm{l})+\mathrm{K}_{3} \mathrm{AlF}_{6}(\mathrm{l}) \\
2 \mathrm{KBF}_{4}+3 \mathrm{Al}(\mathrm{l}) \rightarrow \mathrm{AlB}_{2}+2 \mathrm{KAlF}_{4}
\end{gathered}
$$

On cooling $\left(697^{\circ} \mathrm{C}\right)$ :

$$
\mathrm{Al}(\mathrm{l})+\mathrm{Al}_{5} \mathrm{~W} \rightarrow \mathrm{Al}_{12} \mathrm{~W} \text { (peritectic) }
$$

On cooling $\left(661^{\circ} \mathrm{C}\right)$ :

$$
\mathrm{Al}(\mathrm{l})+\mathrm{Al}_{12} \mathrm{~W} \rightarrow \mathrm{Al}(\mathrm{s}) \text { (peritectic) }
$$

On cooling $\left(666^{\circ} \mathrm{C}\right)$ :

$$
\mathrm{Al}(\mathrm{l})+\mathrm{Al}_{3} \mathrm{Ti}(\mathrm{s}) \rightarrow \mathrm{Al}(\mathrm{s}) \text { (peritectic) }
$$

Comparison of Figs. 1a and $1 \mathrm{~b}$ shows that particle yield is higher in the case of $\mathrm{K}_{2} \mathrm{TiF}_{6}$. This may be attributed to: a) the release of Ti within the molten alloy, which as a surface active element, reduced the melt surface tension and enhanced the particle-molten alloy wetting behavior, and b) the comparatively high slag fluidity. More analytically, according to reaction (3), the $\mathrm{K}_{2} \mathrm{TiF}_{6}$ introduction into the melt leads to the formation of a two compound slag ( $\mathrm{KAlF}_{4}$ and $\mathrm{K}_{3} \mathrm{AlF}_{6}$ of 3 to 1 molar ratio); 


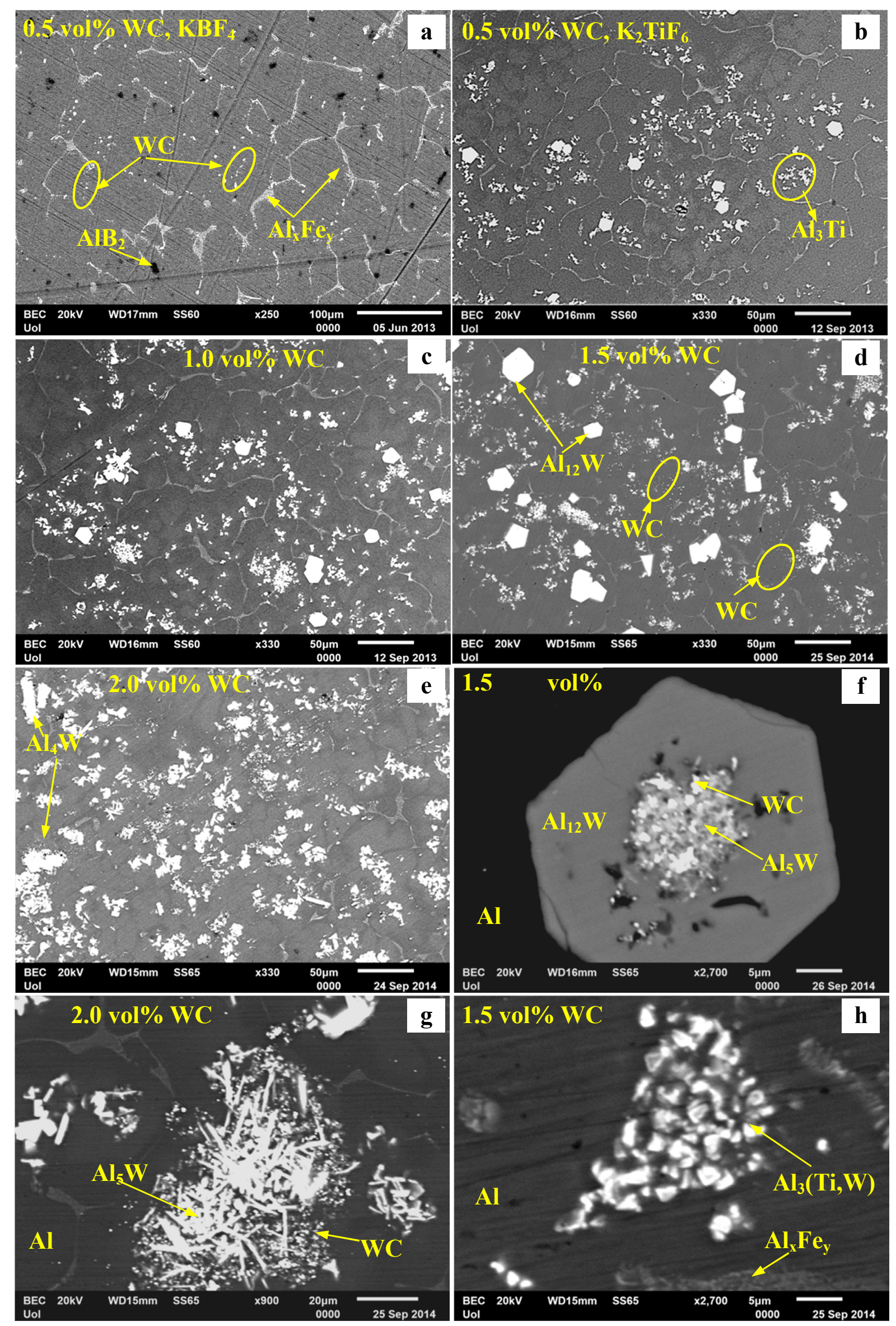

Fig. 1. The microstructure of the composites. (a) $\mathrm{KBF}_{4}$ addition; (b-h) $\mathrm{K}_{2} \mathrm{TiF}_{6}$ addition; (f) a coagulate of WC nanocores and bundles of $\mathrm{Al}_{5} \mathrm{~W}$ acicular plates within an $\mathrm{Al}_{12} \mathrm{~W}$ crystal; $(\mathrm{g})$ bundles of $\mathrm{Al}_{5} \mathrm{~W}$ needles located by/on WC nanocores; (h) a cluster of $\mathrm{Al}_{3}(\mathrm{Ti}, \mathrm{W})$ particles on a bed of WC nanocores in the interior of an $\mathrm{Al}$ grain 
on the other hand, the $\mathrm{KBF}_{4}$ introduction into the melt leads to the formation of a one compound slag $\left(\mathrm{KAlF}_{4}\right)$. The system $\mathrm{K}_{3} \mathrm{AlF}_{6}-\mathrm{KAlF}_{4}$ presents a eutectic point at $558^{\circ} \mathrm{C}$ [31]; $\mathrm{KAlF}_{4}$ has a melting point of $575^{\circ} \mathrm{C}$. Therefore, at the processing temperature of $830^{\circ} \mathrm{C}$, the two-compound based slag formed by the reaction of molten $\mathrm{Al}$ with $\mathrm{K}_{2} \mathrm{TiF}_{6}$ is very likely to be more superheated than the sole $\mathrm{KAlF}_{4}$ slag formed by the reaction of $\mathrm{Al}$ with $\mathrm{KBF}_{4}$. As such, the $\mathrm{K}_{3} \mathrm{AlF}_{6}-\mathrm{KAlF}_{4}$ slag should exhibit higher fluidity. Another potential reason for the relatively high fluidity of the $\mathrm{K}_{3} \mathrm{AlF}_{6}-\mathrm{KAlF}_{4}$ slag could be the intensively exothermic reaction of $\mathrm{K}_{3} \mathrm{TiF}_{6}$ with $\mathrm{Al}$ as compared to the reaction of $\mathrm{KBF}_{4}$ with $\mathrm{Al}[30]$.

Irrespectively of the fluxing agent and the WC content, Fig. 1a-e shows that particle distribution is characterized by both clustered and isolated particles located mainly at the grain boundaries and the areas of the last to solidify liquid. Clustering can be due to the submicron particle size and/or particle pushing by the solidifying front. Particle pushing is responsible for the final particle intergranular location: Upon cooling, the hotter due to their lower thermal conductivity - particles (in this case $\mathrm{WC}, \mathrm{Al}_{3} \mathrm{Ti}$ and $\mathrm{AlB}_{2}$ ) sustain the surrounding liquid at higher temperatures, thus inhibiting the growth of an advancing grain [32]. Consequently, grain refinement occurs and particles are pushed towards the grain boundaries.

In all cases, there was strong evidence of particle-matrix reactivity, especially in the case of $\mathrm{K}_{2} \mathrm{TiF}_{6}$. All phases have been identified by EDX analysis. A variety of intermetallic compound (IC) phases have been formed by reactions (1) to (7). Regarding the case of $\mathrm{K}_{2} \mathrm{TiF}_{6}$ employment, the occurrence and topography of coarse polygonal particles of $\mathrm{Al}_{12} \mathrm{~W}$ is attributed to a sequence of peritectic reactions (5) \& (6), the microstructural outcome of which is clearly illustrated in Fig. 1f, namely: $\mathrm{Al}_{5} \mathrm{~W}$ particles are engulfed by the growing $\mathrm{Al}_{12} \mathrm{~W}$ grain; $\mathrm{Al}_{12} \mathrm{~W}$ in turn is engulfed by the growing $\mathrm{Al}$ grain. The co-presence of WC nanoparticles (actually, remaining cores after reaction of original submicron WC particles with the Al-melt) and $\mathrm{Al}_{5} \mathrm{~W}$, observed in Fig. 1f, is justified by reaction (1). Fig. $1 \mathrm{~g}$ manifests a typical outcome of reaction (1), where needles of $\mathrm{Al}_{5} \mathrm{~W}$ are associated with $\mathrm{WC}$ cores/nanoparticles. In Fig. $1 \mathrm{~h}$, the $\mathrm{Al}_{3}(\mathrm{Ti}, \mathrm{W})$ phase, a product of reaction (3), appears as dispersed clusters of cuboidal platelets associated with WC nanoparticles. The co-occurrence of WC nanoparticles and the presence of $\mathrm{W}$ in solid solution with $\mathrm{Ti}$ in the $\mathrm{Al}_{3} \mathrm{Ti}$ structure, indicate that $\mathrm{WC}$ particles have functioned as heterogeneous nucleation sites. Besides being located intergranularly, $\mathrm{Al}_{3}$ Ti phase is also frequently found inside $\mathrm{Al}$ grains (Fig. 1h), a location justified by peritectic reaction (7).

In contrast with the case of $\mathrm{K}_{2} \mathrm{TiF}_{6}$, in the case of $\mathrm{KBF}_{4}$ addition, the presence of the $\mathrm{AlB}_{2}$ precipitates is not associated with the presence of the WC particles (Fig. 1a), which suggests that the latter did not act as nucleation sites for $\mathrm{AlB}_{2}$. It should be mentioned that not any reaction products in the vicinity of the WC particles can be observed, indicating limited reactivity between $\mathrm{WC}$ and Al. This limited reactivity suggests slow reaction kinetics, most likely a consequence of the coarse $\mathrm{Al}$ grain size (compare Fig. 1a with Fig. 1b). The coarse grain structure is attributed to the limited population of boride precipitates, which may in turn be explained by the slow rate of reaction (4) and limited grain refining efficiency [20,30].

Fig. 1 also reveals the presence of intergranular eutectic phases of Al-Fe and, more rarely, Al-Fe-Si intermetallic compounds. These phases are common impurities in commercial Al-alloys [33] and have been shown to play a major role on the corrosion response of these AMCs [22].

The uniform distribution of intermetallic particles and WC nanoparticles/cores, as clusters and individual particles, defines a novel composite structure containing in-situ reinforcement (intermetallic phase) and ex-situ reinforcement (WC). Section 3.2 is tackling with two issues:

(a) whether the resulting structure has superior wear performance with respect to the $\mathrm{Al}$ alloy, and

(b) how far can one go with the carbide volume fraction in terms of surface property improvement?

\subsection{Sliding wear response}

Fig. 2a shows that the mass loss increases with the sliding distance, as also observed in several works concerning cast PRAMs [22,23,25,34]. Fig. 2a also manifests the beneficial action of the WC content in the mass loss reduction and, consequently, wear rate reduction. The microstructural observations in section 3.1 suggest that WC particles benefit the wear resistance of the composites both directly (as particles and cluster constituents) and indirectly (through the hard intermetallic particles resulting from the reaction of $\mathrm{WC}$ with $\mathrm{Al}$ or the heterogeneous nucleation at WC sites). The reinforcement (carbides and aluminides) can delay plastic deformation manifestations in the soft matrix by: a) reducing the load transfer to the matrix (especially the coarse IC particles and clusters), (b) decreasing the surface area of the metallic matrix, (c) decreasing the direct matrix-counterface contact area, (d) delaying thermal softening of the matrix, and (e) inducing Al-grain refinement. However, despite the aforementioned positive contributions, Fig. 2a shows that increasing the CVF from $1.5 \%$ to $2.0 \%$ has only induced a marginal decrease in the wear rate, which will be discussed in next paragraphs.

Fig. $2 \mathrm{a}$ also reveals that composites prepared by $\mathrm{K}_{2} \mathrm{TiF}_{6}$ addition present lower wear rates than their counterparts prepared by $\mathrm{KBF}_{4}$ addition, attributed to: (a) denser dispersion of IC and WC particles and, correspondingly, lower surface area of the Al matrix, and (b) cleaner and stronger interfaces due to improved particle insertion. The wear track morphology in Fig. $2 \mathrm{~b}$ reflects the inferior wear response of the composites prepared by $\mathrm{KBF}_{4}$, namely: The Al-1.0 vol\% $\mathrm{WC}\left(\mathrm{KBF}_{4}\right)$ material presents the most severe plastic deformation (highest occurrence of ridges, roughest profile of wear track edges and widest wear track).

Anyway, in all cases of Fig. 2b, the "hill-valley" morphology (also characterizing the wear surface of other cast PRAMS, such as Al- $\mathrm{Mg}_{2} \mathrm{Si}-\mathrm{TiC}$ and $\left.\mathrm{Al}-\mathrm{MoSi}_{2}[34,35]\right)$, is observed. Such landscape formation signifies intensive plastic deformation that 


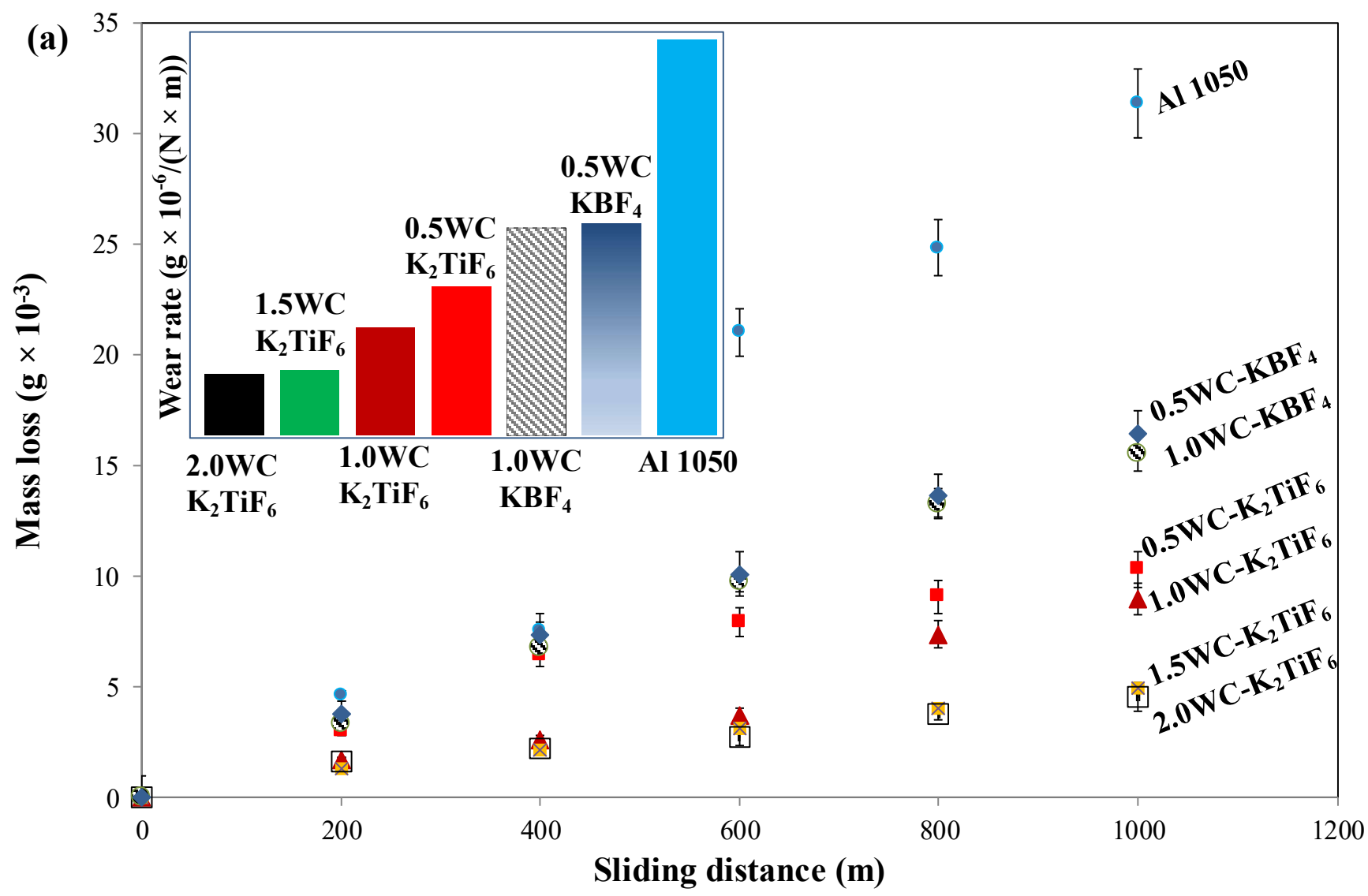

(b)
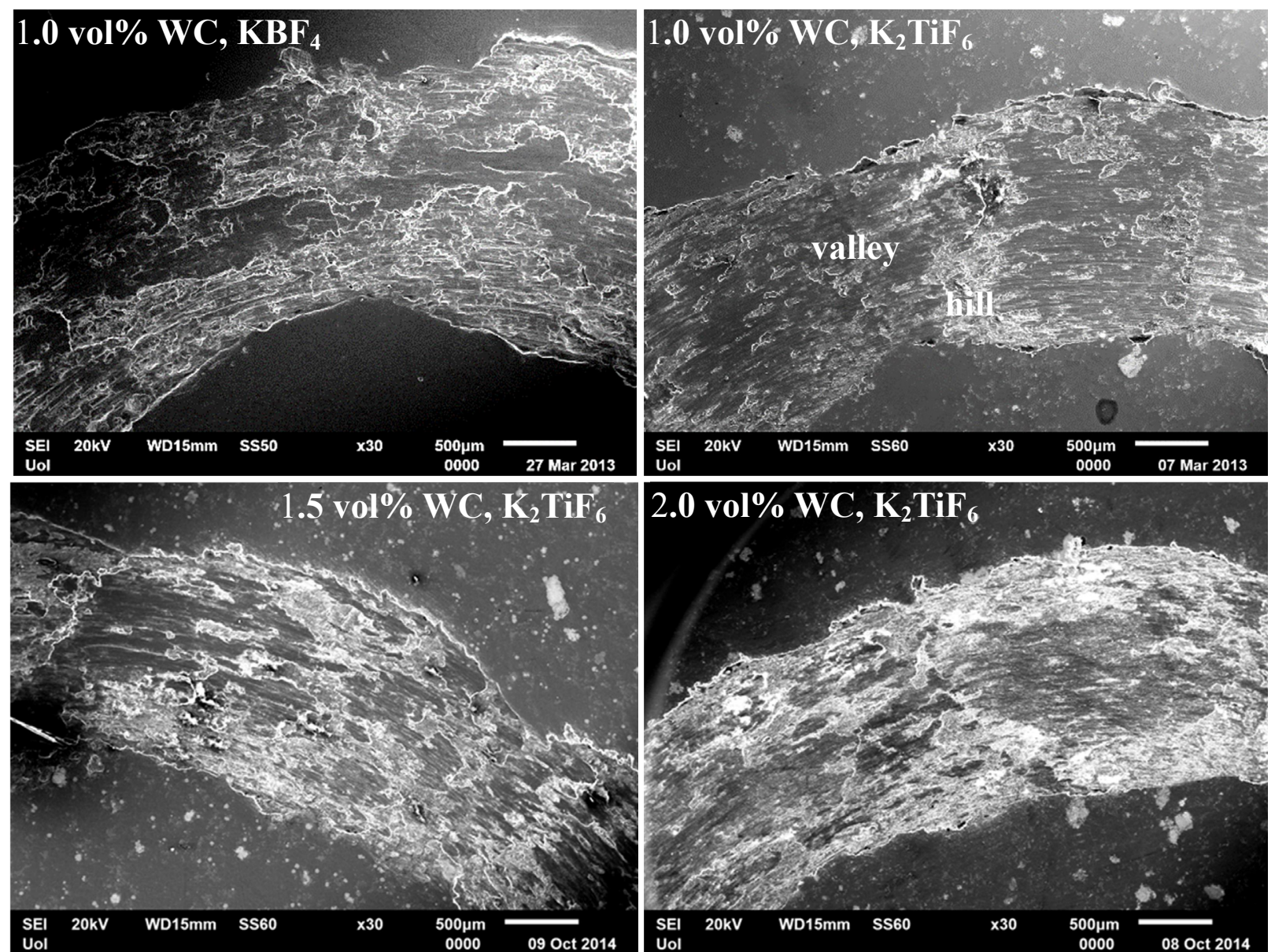

Fig. 2. (a) Mass loss as a function of sliding distance and extracted wear rates in the inset; (b) wear track morphologies of the composites 
eventually builds a hump ahead of the steel ball counterface. Strain hardening effects restrain the hump from growing and the steel ball overpasses it repeating the same cycle on a nearby area [36]. A most interesting notice in Fig. 2b, is that the wear track morphology of the $2.0 \mathrm{vol} \%$ WC AMC gives the impression of great surface upheaval (intensively bright surface regions), discussed in the following paragraphs.

A closer inspection of selected areas of the wear tracks in Fig. 3 leads to the following observations: The presence of crack/flaws (on oxidized layers) almost perpendicular to the sliding direction (Figs. 3a and $b$ ), is associated with either plastic deformation phenomena and/or thermal fatigue of the oxide phases due to temperature fluctuations as the test was interrupted every $200 \mathrm{~m}$ for specimen weighing. Figs. $3 \mathrm{a}$ and $\mathrm{b}$ also show that areas rich in aluminides are free of cracks. Fig. $3 \mathrm{c}$ displays extensive oxide formation attributed to the high temperatures developed during sliding. Figs. $3 \mathrm{~d}$ and $3 \mathrm{e}$ give an insight into the rough profile of the Al-2.0 vol\% WC wear track observed in Fig. 2b. Fig. 3d reveals very rough wear surfaces on hills, indicating extensive material transfer and upheaval. EDX mapping confirms the non-uniform composition of the hills, whilst manifesting the deposition of a thick mechanically mixed layer (MML) in compatibility with the slow mass loss increase versus sliding distance for this composition observed in Fig. 2a. On the other hand, valleys show a much smoother relief and a more homogeneous composition (Fig. 3e). Finally, it should be noted that EDX analysis of debris particles showed that they consist of sintered particles of alumina with minor amounts of $\mathrm{W}$ and traces of Ti and occasionally Fe. The abrasive action of debris is considered responsible for the fine grooves observed along the sliding direction (Fig. 3a-c,e).

Based on the above observations, two different wear mechanisms can be formulated for the low CVF AMCs and the high CVF AMCs of this effort:

$A M C s$ with $W C \leq 1.5$ vol\%: On the onset of the wear experiment, intensive plastic deformation of the Al-matrix in front of the counter-body occurs leading to notable material flow and, eventually, the periodic "hill-valley" morphology. At the same time, surface alumina layers (slightly enriched by W) are formed owing to frictional heating. Cracks are grown on these layers, due to the brittleness of the oxides and wear fatigue intensified by thermal fatigue. Although crack propagation is retarded by the dispersed aluminide/WC particles and clusters, it eventually leads to material loss and debris formation. The abrasive action of debris causes the formation of fine grooves on the wear surface.

AMCs with $W C=2.0$ vol\%: The Al-matrix deformation-due periodic "hill-valley" morphology results as well. Due to the increased agglomeration of aluminide/WC particles, a considerable amount of Al-matrix remains dispersion-poor and, as such, it is subjected to more severe deformation (ploughing) and hill formation. Coarse segregates of aluminide/WC particles become loosened and detached causing third body abrasion on the Alsubstrate. Dynamic mixing and sintering of agglomerates with alumina from the hills and debris cause extensive formation of a thick alumina MML on the hills. The MML at the hills is very rough delaying crack propagation. It should be noted that crack propagation at the softer valleys is also limited, since the frictional forces are higher at the hills. To conclude, two countermechanisms lead to a wear rate that is slightly lower than that of the $1.5 \mathrm{vol} \%$ AMC: On one hand, severe plastic deformation of $\mathrm{Al}$ in dispersion-poor regions and detachment of the segregated reinforcement with consequent abrasive action play a negative role on the wear performance of the AMCs. On the other hand, the thick and rough MML on the hills plays a positive role on the wear performance of the AMCs by protecting the substrate and delaying crack propagation. Higher WC additions (under the employed casting parameters) are expected to increase reaction phase segregation, further deteriorating the AMC wear performance.

\section{Conclusions}

Al1050 composites ex-situ reinforced with sub-micron WC particles were fabricated through a modified stir-casting method using $\mathrm{KBF}_{4}$ and $\mathrm{K}_{2} \mathrm{TiF}_{6}$ salts as wetting enhancement agents. The employment of $\mathrm{K}_{3} \mathrm{AlF}_{6}$ and $\mathrm{Na}_{3} \mathrm{AlF}_{6}$ as wetting agents did not have any promoting effect on particle insertion into the Al melt.

The reactivity between the molten alloy and the reinforcement was high, especially in the case of $\mathrm{K}_{2} \mathrm{TiF}_{6}$ flux. The uniform distribution of intermetallic particles, WC nanoparticles and intermetallic/nanocarbide clusters defines a novel composite material containing in-situ reinforcement (submicron $\mathrm{Al}_{3}(\mathrm{Ti}, \mathrm{W})$, micron $\mathrm{Al}_{12} \mathrm{~W}$-only in CVFs $<2.0 \mathrm{vol}^{2}$-, $\mathrm{Al}_{5} \mathrm{~W}$ and $\mathrm{Al}_{4} \mathrm{~W}$-only in $\mathrm{CVFs}>1.0 \mathrm{vol}^{\circ-}$ ) and ex-situ reinforcement (WC nanoparticles, as such, or as clusters with aluminide particles).

The sliding wear performance of the alloy was improved by the addition of the reinforcing particles. Composites prepared by $\mathrm{K}_{2} \mathrm{TiF}_{6}$ addition presented lower wear rates than their counterparts prepared by $\mathrm{KBF}_{4}$ addition. Al low CVFs $(\leq 1.5 \%)$, crack propagation was delayed by the dispersion. At high CVFs $(2.0 \%)$, crack propagation was obstructed by a tribolayer but, at the same time, severe plastic deformation of $\mathrm{Al}$ occurred in dispersion-poor regions.

\section{Acknowledgments}

To the Greek General Secretariat for Research \& Technology and the European Commission (NSRF 2007-2013) (Joint Research \& Technology Programs /Hellas-Hungary); to Ms. V. Gousia for conducting some of the experiments.

\section{REFERENCES}

[1] R. Casati, M. Vedani, Metals 4, 65 (2014).

[2] Subhranshu Chatterjee, Amitava Basu Mallick, Mater. Sci. Forum 36, 72 (2013). 

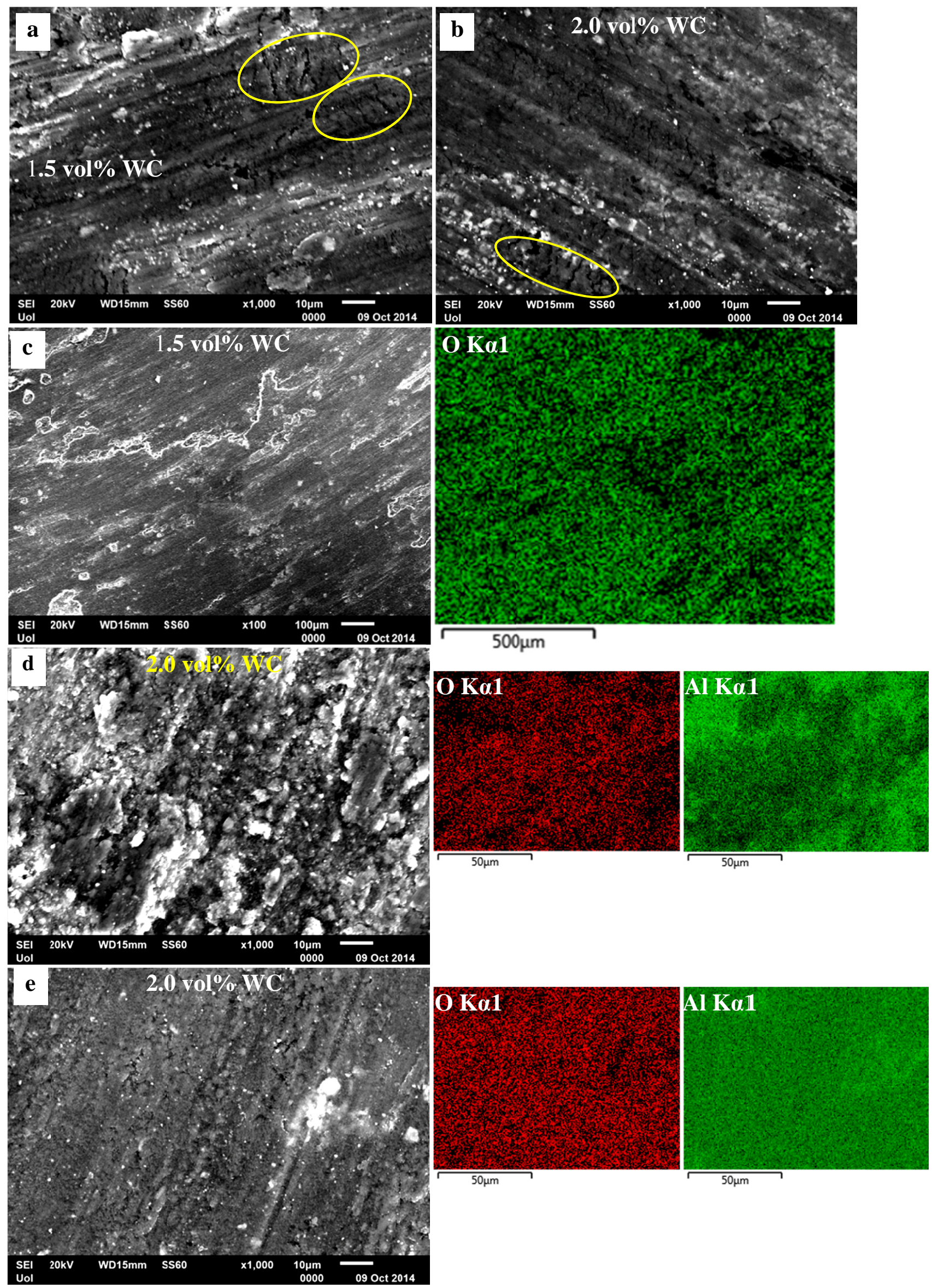

Fig. 3. Selective areas of the wear tracks. (a), (b) cracks perpendicular to the sliding direction; (c) extensive oxide formation manifested by oxygen mapping; (d) rough mechanically mixed layer on a hill of non- uniform composition ( $\mathrm{O}$ and $\mathrm{Al}$ mapping); (e) valleys show a relatively smooth relief and homogeneous composition ( $\mathrm{O}$ and $\mathrm{Al}$ mapping) 
1242

[3] D. Kumar Koli, G. Agnihotri, R. Purohit, Procedia Mater. Sci. 6, 567 (2014).

[4] G.U. Wan-Li, Trans. Nonferrous Met. Soc. China 16, 398 (2006).

[5] H.R. Lashgari, Sh. Zangeneh, H. Shahmir, M. Saghafi, M. Emamy, Mater. Design 31, 4414 (2010).

[6] M. Hossein-Zadeh, M. Razavi, O. Mirzaee, R. Ghaderi, J. King Saud University - Engineering Sciences 25, 75 (2013).

[7] H. Abdizadeh, R. Ebrahimifard, M.A. Baghchesara, Compos. B Eng. 56, 217 (2014).

[8] J. Wang, D. Yi, X. Su, F. Yin, H. Li, Mater. Design 30, 78 (2009).

[9] M. Karbalaei Akbari, S. Rajabi, K Shirvanimoghaddam, H.R. Baharvandi, J. Compos. Mater. 49, 3665 (2015).

[10] I. Narasimha Murthy, D. Venkata Rao, J. Babu Rao, Mater. Design 35, 55 (2012).

[11] Hao Yu. Processing Routes for Aluminum based Nano-Composites. MSc Thesis, Worcester Polytechnic Institute, April 2010.

[12] A. Evirgen, M. Lütfi Övecoglu, J. Alloy Compd. 496, 212 (2010).

[13] A R.K. Swamy, A. Ramesha, G.B. Veeresh Kumar, J.N. Prakash, J. Miner. Mater. Charact. Eng. 10, 1141 (2011).

[14] A. Simon, D. Lipusz, P. Baumli, P. Balint, G. Kaptay, G. Gergely, A. Sfikas, A. Lekatou, A. Karantzalis, Z. Gacsi, Arch. Metall. Mater. 60, 1517 (2015).

[15] G.B.V. Kumar, A.R.K. Swamy, A. Ramesha, J. Compos. Mater. 46, 2111 (2012).

[16] A.E. Karantzalis, A. Lekatou, E. Georgatis, Th. Tsiligiannis, H. Mavros, J. Mater. Eng. Perform. 19, 1268 (2010).

[17] K. Kalaiselvan, I. Dinaharan, N. Murugan, Mater. Design 55, 176 (2014).

[18] K.L. Juhasz, P. Baumli, J. Sytchev, G. Kaptay, J. Mater. Sci. 48, 7679 (2013).
[19] A.E. Karantzalis, A. Lekatou, E. Georgatis, V. Poulas, H. Mavros, J. Mater. Eng. Perform. 19, 585 (2010).

[20] Y. Birol, J. Alloy Compd. 440, 108 (2007).

[21] A.R. Kennedy, A.E. Karantzalis, Mater. Sci. Forum 217-222, 253 (1996).

[22] A. Lekatou, A.E. Karantzalis, A. Evangelou, V. Gousia, G. Kaptay, Z. Gácsi, P. Baumli, A. Simon, Mater. Design 65, 1121 (2015).

[23] G.B.V. Kumar, C.S.P. Rao, N.J. Selvaraj, J. Miner. Mater. Character. Eng. 10, 59 (2011).

[24] R.L. Deuis, C. Subramanian, J.M. Yellup, Compos. Sci. Technol. 57, 415 (1997).

[25] M. Kök, K. Özdin, J. Mater. Process. Technol. 83, 301 (2007).

[26] R.S. Rana, R. Purohit, S. Das, Int. J. Scientific Research Publications 3 (9), 1 (2013).

[27] K.K. Ekka, S. R. Chauhan, Varun, Arab. J. Sci. Eng. 40, 571 (2015).

[28] D.R. Lide (ed.), CRC Handbook of Chemistry and Physics, CRC Press, 1991-1992.

[29] H. Baker (ed.), ASM Handbook, vol. 3: Alloy Phase Diagrams, $9^{\text {th }}$ ed., ASM Intern. Materials Park, OH, (1997).

[30] N. El-Mahallawy, M.A. Taha, A.E.W. Jarfors, H. Fredriksson, J. Alloy Compd. 221, 29 (1999).

[31] R. Chen, G. Wu, Q. Zhang, J. Am. Cer. Soc. 83, 3196 (2000).

[32] M.K. Surrapa, P.K. Rohatgi, J. Mater. Sci. 16, 983 (1981).

[33] E. Georgatis, A. Lekatou, A.E. Karantzalis, H. Petropoulos, S. Katsamakis, A. Poulia, J. Mater. Eng. Perform. 22, 729 (2013).

[34] H. Mavros, A.E. Karantzalis, A. Lekatou, J. Compos. Mater. 47, 2149 (2013).

[35] V. Gousia, A. Tsioukis, A. Lekatou, A.E. Karantzalis, J. Mater. Eng. Perform., (2016), DOI: 10.1007/s11665-016-1947-1.

[36] A.D. Sarkar, Friction and wear, Academic Press, London, 1980. 